\title{
Perspectives on Aging among Graduate Social Work Students: Using Photographs as an Online Pedagogical Activity
}

\author{
Jill M. Chonody \\ Boise State University \\ jillchonody@boisestate.edu
}

\begin{abstract}
The United States is experiencing an aging of the population, and by 2030, $20 \%$ of Americans will be 65 years or older (Federal Interagency Forum, 2010). However, for many helping professions, including social work, medicine, and nursing, student interest in gerontological practice is quite low. One international study found that only 5.4\% of the more than 1,000 social work students who were surveyed indicated that working with older people was their primary area of interest (Chonody \& Wang, 2014). Finding ways to improve student interest and break down biases against older adults is essential to improve student interest, and incorporating evidence-based activities that can be incorporated into courses that are offered in an online format are increasingly needed as this mode of instruction continues to expand. The current exploratory study sought to pilot a two-part photo-activity in an online graduate social work practice course focused on working with older adults. Quantitative and qualitative results suggest that the activities helped students' process their views on aging and older people, and most students reported at least some change in their attitudes. The development of innovative ways to engage students online by repurposing technology that they are already using can advance online pedagogy and facilitate critical thinking.
\end{abstract}

Keywords: ageism, aging attitudes, pedagogical intervention, online platform

Social work is a diverse field with opportunities to work with many different populations; however, gerontological practice consistently ranks amongst the lowest preferred practice area (Weiss, 2005). An international study found that only 5.4\% of the more than 1, 000 social work students who completed the survey indicated that they would prefer to work with older adults after graduation (Chonody \& Wang, 2014). In a study of nursing students, working with older people in a nursing home setting was ranked the lowest preferred practice setting, and this did not significantly change from the start of the nursing program (King, Roberts, \& Bowers, 2013). These findings are troublesome for helping disciplines given that $20 \%$ of the total U.S. population is expected to be 65+ by 2030 (Federal Interagency Forum, 2010). Thus, an urgent need for helping professionals in gerontological practice is becoming a reality, and educators are searching for ways to increase student interest (Butler \& Baghi, 2008; Chonody, 2015).

Research indicates that both lack of knowledge about aging (Goncalves et al., 2011) and ageist attitudes (Kane, 2007) are contributing factors to low student interest in gerontological practice. Attempts to change students' attitudes have included infusion of content in a course, service learning, and aging electives. Results indicate that both instructional as well as experiential approaches can have an impact on student attitudes (Funderburk, DamronRodriguez, Storms, \& Solomon, 2006; Hwang, Wang, \& Lin, 2013; Synder, 2006; Gutheil, Chernesky, \& Sherratt, 2006;). Increased knowledge helps challenge myths thus improving students' understanding of aging and older adulthood (O'Hanlon \& Brookover, 2002). The experiential component is consistent with Allport's (1954) contact theory, which asserts that 
exposure to members of an out-group can reduce prejudice. Research in social cognition suggests that contact allows empathy and perspective taking to occur; this in turn, helps to break down prejudicial attitudes (Castillo, Camara, \& Eguizabal, 2011), and a review of the literature supports that contact with older adults is associated with more positive attitudes (Wang \& Chonody, 2013).

In a recent systematic review of the literature, 58 articles that described pedagogical interventions aimed at influencing aging knowledge, attitudes toward older adults, and/or interest in gerontological practice across multiple academic disciplines, including social work, nursing, and medicine, were identified. Results indicated that improving gerontological interest was the most challenging and the least studied of the three areas (Chonody, 2015). Moreover, 95\% of all of these studies occurred in traditional, face-to-face courses or workshops (Chonody, 2015). This dearth of research on pedagogical approaches for online courses in the extant literature is problematic given the increased demand for more courses offered in this format. The development of methods that rely on the best possible strategies for creating change will further advance evidence-based practices for online instruction. Further, the use of a theoretically driven model to derive a pedagogical activity grounds the application in a rich body of knowledge that provides insight into why it works. The current study implemented a photography based pedagogical intervention in an asychronous online graduate level aging course to pilot its application.

\section{Photography and Instructional Methods}

Photography is increasingly an element of our day-to-day lives as smart phones have made taking pictures easily accessible and virtually limitless (Chonody \& Amitrani-Welsh, 2014). It is also a form of communication (Van Dijck, 2008) as images are widely shared through social media platforms and amongst one another via text. Many people, in particular young adults, use photography as a way to generate conversations and strengthen connections within the peer group (Van Dijick, 2008). Smart phone applications such as Snapchat or Instagram primarily rely on an image often absent of any text and put forward an idea, a point in time, and/or an element of identity. This cultural shift illustrates the way that old technology is repurposed, and a new means of interaction and community building emerges (Van Dijick, 2008).

To process the symbolic representation of the visual information relies on a part of the brain that is older than the part that is used to process verbal information (Harper, 2002). "Thus, images evoke deeper elements of human consciousness than do words” (Harper, 2002, p. 13). Arts-based methods of inquiry can shed light on topics that are complex or challenging to explore (Black, 2011), which may be social or personal in nature (Hagedorn, 1996), and selfexploration and reflection can be generated through the use of photography (Chonody \& Amitrani-Welsh, 2014; Weiser, 2013). When respondents are asked to view and interpret a photograph, they are actively seeking to assign meaning to the visual stimulus (Harrison, 2002). The images may be self-created, but this is not necessary for the process of "reading" the photograph (Harrison, 2002). That is, respondents can engage with visual information and interpret it and making meaning even if they were not the originators of the material.

Arts-based methods, particularly photography, can be useful as a pedagogical activity (Leavy, 2009). Engagement with students, especially those that are "wired” (e.g., born into the computer era), in a way that takes advantage of their perspective on the world can more readily generate reflection skills given that they are realized through a skill set that they are already

Journal of the Scholarship of Teaching and Learning, Vol. 18, No. 2, June 2018. josotl.indiana.edu 
comfortable in using (Tornabene, Versnik Nowak, \& Vogelsang, 2012). By coupling narratives with photographs not only is student engagement improved, but instructors can also gage the depth and breadth of student learning (Tornabene et al., 2012) given that these methods "can reveal tacit knowledge and make knowledge and meaning construction visible” (Black, 2011, p.68).

The use of photography in the educational settings, either for research or pedagogical purposes or both, primarily draws from Photovoice (Wang \& Burris, 1997) and photo elicitation methods (Collier, 1957). Photovoice relies on the individual creation of photographs around a particular topic, which are then deconstructed using a framework of questions that seek to reveal the deeper meaning and symbolic representation within the photograph (Wang \& Burris, 1997). For example in a study of high school students in Philadelphia, Photovoice was implemented to explore the presence and experience of violence by looking at neighborhood assets and challenges (Chonody, Ferman, Martin, \& Amitrani-Welsh, 2013). Photo elicitation, a research technique used in anthropology and sociology, is a technique that facilitates conversations about thoughts and feelings that may be difficult to access when not accompanied by visual stimulation (Hagedorn, 1996), particularly in participant interviews (e.g., Collier, 1957). Participants are shown photographs, typically supplied by the researcher, that are used to generate conversation around related topics.

There is limited research evidence on the use of arts-based methods in higher education as a pedagogical method to initiate critical thinking and garner greater depth of understanding around particular content. Even fewer studies exist for pedagogical methods implemented in online courses; however, some literature across various disciplines was identified. Each of these is reviewed here as they informed the development of the photo activity that was implemented in the current study.

In an application of Photovoice, photography was used to help students deconstruct gender in a traditional classroom setting (Robinson-Kellig, Hamill, Gwin-Vinsant, \& Dashner, 2014). Data were not collected on either student responses to the photo activity or changes in knowledge/perception, but the authors report that the project was successful in that students were engaged in critical thinking about socially ascribed roles and took ownership over their own learning (Robinson-Kellig et al., 2014). In a similar article, instructors aimed to improve critical thinking and problem solving skills for health science students through engagement with either Photovoice or photo elicitation (Ott Walter, Baller, \& Kuntz, 2012). In the Photovoice activity, students took pictures around campus to represent the impact of alcohol and drug use. For the photo elicitation activity, students first took pictures of various dimensions of health, and then as a class, the "best representations" for the ten dimensions of health were determined through a voting process. Finally, each student then provided individual interpretations of the photographs. These activities were not formally evaluated, but Ott Walter and colleagues (2012) note that the use of photography to achieve classroom goals provided "a creative way to simultaneously address two separate issues: awareness of social problems or determinants of health and engagement in critical thinking” (p. 386). They also point to the fact that students were able to develop a new perspective on the issue by reflecting on the photographs, and their written responses to the photographs are indicative of increased awareness of their environment (Ott Walter et al., 2012).

Likewise, Chio and Fandt (2007) discuss the use of Photovoice within a face-to-face diversity class, which had around 80 students enrolled in it over the course of two years. Again, a formal evaluation of student learning or attitudinal change was not included, but the authors do

Journal of the Scholarship of Teaching and Learning, Vol. 18, No. 2, June 2018. josotl.indiana.edu 
highlight several lessons learned from its implementation. First, the authors state that they continue to learn about themselves through use of the Photovoice process, which is important for ongoing consideration of one's social position and location. They also acknowledged the strengths that are brought out in students as they make themselves vulnerable and were opened up to this challenging learning experience. Moreover, photovoice created a context for communication and knowing that could move beyond categories (e.g., teacher) and bring forward the true nature of learning as a two-way process- "flowing from them to us" (Chio \& Fandt, 2007, p. 495).

Only one article was identified that was related to gerontology, employed an arts-based pedagogical technique, and used the activity in an online course (sociology of aging). This study sought to explore students' aging beliefs and the intersection of gender and age through drawings of older adults, which were generated by current and previous students (Barrett \& Pai, 2008). Students analyzed patterns found in the sketches and then participated in asynchronous online discussion, which generated a conversation around ageism and the intersectionality.

Data were collected in the form of a formal evaluation of the activity as well as the actual interpretations of the sketches. The four most common themes that materialized from the discussion of the sketches were: ageist beliefs reflected in the drawings, the impact of intergenerational contact in shaping views of older people, the role of the media, and gender differences. Students identified both positive and negative ageist beliefs, including wisdom, knowledge, stubborn, ill-tempered, grumpy, wrinkled, snobbish, and lonely, and discussed how these stereotypes may develop, including contact with older people, age-segregation, and the media. To evaluate the activity itself, students completed an anonymous online survey, and the overall responses were primarily positive. In particular, a majority of the students (63\%) indicated that the sketch discussion was effective in stimulating their thinking around ageism, and 93\% reported that they enjoyed the discussion. In terms of reported attitudinal change, 39\% related that their perspective on older people was now more positive. These results are promising for the use of visual materials to generate discussion around complex topics in online courses, and the potential to influence changes in thinking.

\section{Current Study}

Building on the photo-activities developed in these other projects, a new photography-based activity was developed for an online aging course. Specifically, this activity centered on selfreflection, group discussion, and critical thinking. The self-reflection component took the form of a two-part activity. First, students posted a photograph on the online discussion board in their learning management system (Canvas) to illustrate their perspective on aging and included a description of why this photograph was chosen. Second, an online discussion of aging was facilitated the following week by processing the entirety of the photographs that were posted by the class. Thus, the activities were intended to create a reduction of in-group favoritism by blurring the (false) distinction between the in-group (young) and the out-group (old) through identifying similarities and critically evaluating perceptions of older adulthood.

\section{Methods}

For this case study, data were collected from graduate social work students at a Midwestern university who were enrolled in a 6-week summer course $(2015,2016)$ entitled Social Work

Journal of the Scholarship of Teaching and Learning, Vol. 18, No. 2, June 2018. 
Practice with Older Adults. The course was taught by the same instructor in an asynchronous online format, and the content and structure was exactly the same for both times that the course was taught, including prerecorded lectures and notes on the topic for that week. The Institutional Review Board (IRB) approved this study prior to data collection.

Students were asked to complete a short survey at the beginning of the semester (week 1) and again at the end of the course (week 6; described below). In addition, students participated in discussions on their perception of aging. The first discussion board (week 1) instructions were as follows:

- $\quad$ Post a photo that represents your perspective on aging or your idea of "old."

- Consider these two questions: Why did you choose this image to represent aging or your idea of "old?" What does it mean to be aging or "old" (personally and/or culturally)?

The second discussion board (week 2) instructions asked students to review a PowerPoint slide show created by the instructor from the photographs posted the previous week and then:

- Consider the following questions: What patterns do you notice in the images? What cultural messages are communicated about aging (and are they represented here)? How does it make you feel to think about being "old?"

Students were given credit for completion of the survey (4 points each), but the survey itself remained anonymous by using an online platform (Qualtrics). A survey acknowledgement linked to the online learning management system for each individual (Canvas) allowed students to earn credit for participation. In other words, students went off site to complete the surveys, but then had to indicate via a "quiz" if they had completed the survey by indicating "true/false" to this question: "I have completed Survey 1 (or 2)."

Students were also graded for their participation in the discussion posts. As per federal guidelines regarding online courses and required time spent in activities related to a course, discussion posts are required nearly all weeks of the course. Thus, for these students, the two photo-based discussion boards were used for both a learning opportunity and as a part of routine class activity expected with an online course.

\section{Measures}

Standardized scale. The Fraboni Scale of Aging (FSA; Fraboni, Saltstone, \& Hughes, 1990) was used to measure the affective and behavioral aspects of ageism. Two subscales of the three subscales FSA were used in this study. These 20-items are evenly divided between subscales for antilocution (e.g., "Teenage suicide is more tragic than suicide among the old”), and avoidance (e.g., "I don't like it when old people try to make conversations with me"). The decision to leave out the discrimination subscale (9-items) was based on a review of the items and finding that the wording was slightly more anachronistic than the other two subscales (e.g., "Old people don't really need to use our community sports facilities), and the content too overt for study participants (e.g., "Old people deserve the same rights and freedoms as do other members of our society"). A 6-point Likert-type scale was provided ( $1=$ strongly disagree to $6=$ strongly agree). After reverse scoring one item, all items are summed to create an overall ageism score. The theoretical range for the FSA was 20-120, and reliability was acceptable in this case study ( $\alpha$ $=.75)$. The FSA was included in both Survey 1 and Survey 2 .

Survey items. A brief demographic section was included on the Survey 1 and included age, contact with older people, relationship with an older adult, and age that the participant considers

Journal of the Scholarship of Teaching and Learning, Vol. 18, No. 2, June 2018. josotl.indiana.edu 
“old.” Interest in gerontological practice (i.e., working with older adults as the primary work setting) was measured by a series of author-created questions. First, students were asked to indicate their primary area of interest (Survey 1 only). Next, students were asked: "How likely do you think it is that you would be working primarily with older adults once finishing your degree?” and a 6-point Likert-type scale was provided ( 1 = very unlikely to 6 = very likely); this item was found on both Survey 1 and Survey 2. Two open-ended questions were also included on Survey 2: "If you would like to work with older adults when you complete your degree, can you please tell me why? Conversely, if you definitely would not like to work with older adults, can you please tell me why?" and "Is there anything else you would like to say about working professionally with older adults? Or about the class?” On Survey 2, students were also asked: "To what extent have your feelings about working with older adults changed since the beginning of the class?” and a 4-point Likert-type scale was provided $(1=$ not at all to $6=$ a great deal $)$.

\section{Data Analysis}

Quantitative Analysis. SPSS 22.0 was used for descriptive analysis of the demographic questions, survey items, and the standardized scale. No nonparametric tests were used to determine if any statistically significant changes occurred on the ageism scale and the likelihood of working with older adults because the surveys were unable to be matched from time 1 to time 2.

Qualitative Analysis. Content analysis was used to code open-ended questions and discussion posts. Themes were generated based on student responses and then grouped together to garner a representation of the findings from the data. Frequencies were recorded for the themes amongst both the written materials and the photographs.

\section{Results}

\section{Demographic Make-Up}

In the first data collection phase (Summer 2015), 24 students were enrolled in the course; however, in the second collection phase (Summer 2016), only nine students took the class making the total number of participants 33. The response rate for Survey 1 was $100 \%$. All the students were female and had a mean age of 32. Over half the participants identified health/hospital as their preferred practice area upon graduation, which is not surprising given that the course is situated within the health concentration for the master's of social work degree. Nonetheless, $18 \%$ indicated gerontological work as their preferred practice area. On average, students also indicated frequently spending time with an older person and rated that relationship good. The average age at which the students would consider themselves "old" was 70, and over a third indicated an age from 80 to 90 . The response rate for Survey 2 was 85\% $(n=28)$. All data collected from phase 1 and phase 2 were merged for analyses. Table 1 provides all the demographic information for the participants. 


\section{Table 1. Demographic Characteristics of the Participants}

\begin{tabular}{lrr}
\hline Variable & Mean (SD) & Frequency \\
\hline Female & & $33(100 \%)$ \\
Age (24-50) & $32.39(7.21)$ & \\
Spend time with older & $2.39(1.06)$ & \\
people & & \\
Relationship with older & $4.48(0.63)$ & \\
adult & & \\
Age considered "old" & $70.19(10.27)$ & \\
50-60 years old & & $7(21.2 \%)$ \\
65-75 years old & & $15(51.4 \%)$ \\
80-90 years old & & $11(33.3 \%)$ \\
Area of practice & & $6(18.2 \%)$ \\
$\quad$ Aging/Gerontology & & $18(54.5 \%)$ \\
Health/Hospital & $4(12.2 \%)$ \\
Adult Mental Health & & $5(15.1 \%)$ \\
$\quad$ Other & & \\
\hline
\end{tabular}

\section{Discussion 1 Post: Visual Representations}

Prior to merging the qualitative data from both sections of the course, the two slide shows generated from student images were reviewed given that each student group viewed a different set of images. While there were some slight variations in the subject matter of the images that were chosen, the slide shows were remarkably consistent across the two groups. After coding the content of the images and the discussion posts, detail and descriptions were not lost. In other words, there was not anything profoundly different between the two groups in their posts that would be pose an issue, and the major themes of the images and posts were found amongst both groups.

The predominant image posted featured an older person ( $n=15)$. Seven of these images were close-ups of the individual's face (women $=3$, men $=4$ ), and three were drawings of someone who looks prototypically old; that is, gray hair and wrinkles. Another five images were an older person receiving care or lying in a hospital bed (women=4, men=1). The next most common type of images was a picture that illustrated the progression of time either with a number of hands or people of different ages. Three other photographs depicted the passage of time more metaphorically (i.e., tree, leaf, candle). Two students posted an image that represented a journey (e.g., a road), while another two posted a picture of their grandmothers not acting/looking "old." The final four photographs were: the AARP logo, a positive meme, a famous person who is 90 but does not appear to be, and older people doing yoga.

Despite the fact that many of the photographs were used to illustrate the visible signs of aging, the themes present in the content of the post were primarily positive $(n=15)$, and even in those responses that were more mixed in their content $(n=11)$, a positive message still dominated. Students discussed that life and aging are a journey, and that this time in life is just the "next chapter," "stage of life," or "just part of life.” Students also discussed the knowledge, experience, advice, and wisdom that older people have along with the "good stories" that they tell. A few 
students discussed the complexity and richness of older age in terms of accomplishments and roles. For example, one student stated,

(photograph of Russian nesting dolls who progressively looked older) I chose this image to represent my idea of "old” because similar to the Matryoshka doll which appears to just be one doll, elderly people have more to them than meets the eye. When you open the Matryoshka doll, you reveal many different dolls, just as when you begin to speak with an elderly person, you realize they have many different layers. They have held many different roles over the course of their lifetime and have had many experiences...To me, aging is just adding another nesting doll, or new role, on top of the smaller nesting dolls, or older roles.

Other positive themes included the idea that old is "just a state of mind" and that many benefits come with being "old," such as senior discounts and retirement. Students also acknowledged that aging is a "beautiful thing" and that they seek to "live life to the fullest." Table 2 provides all of the themes found in the data, the frequency of their occurrence, and a short illustrative quote.

Table 2. Themes for Discussion 1

\begin{tabular}{|c|c|c|}
\hline Theme & Frequency & Illustrative Quote \\
\hline Positive & & \\
\hline $\begin{array}{l}\text { Stage of } \\
\text { life/journey }\end{array}$ & 15 & $\begin{array}{l}\text { I think that getting old means that we are turning the next } \\
\text { chapter in our lives and we are taking on a new role in our } \\
\text { families and society. }\end{array}$ \\
\hline $\begin{array}{l}\text { Wise, advice, } \\
\text { knowledge }\end{array}$ & 11 & $\begin{array}{l}\text { Trees represent wisdom, something that is gained when } \\
\text { you grow old. Becoming old means holding wisdom and } \\
\text { adapting to life's challenges and changing over time. }\end{array}$ \\
\hline Good stories & 7 & $\begin{array}{l}\text {..when one is aging, it means that they have lived a long } \\
\text { life and have acquired many stories and created many } \\
\text { memories to share with others. }\end{array}$ \\
\hline Lived a full life & 5 & $\begin{array}{l}\text { To me, being “old" is a reflection of a life well lived, full } \\
\text { of meaning and purpose. }\end{array}$ \\
\hline $\begin{array}{l}\text { Aging is beautiful, } \\
\text { layered, or } \\
\text { complex }\end{array}$ & 4 & $\begin{array}{l}\text { The human spirit can shine brightly until the end [like that } \\
\text { of the candle]. }\end{array}$ \\
\hline A state of mind & 4 & $\begin{array}{l}\text { Just because you look “old" does not mean that you are } \\
\text { "old”...mind over matter. }\end{array}$ \\
\hline $\begin{array}{l}\text { Retirement, less } \\
\text { work }\end{array}$ & 3 & $\begin{array}{l}\text { Retirement is a time where one can relax, regroup, release, } \\
\text { enjoy family, and travel more. }\end{array}$ \\
\hline $\begin{array}{l}\text { Self-reflection on } \\
\text { life, } \\
\text { accomplishments }\end{array}$ & 3 & $\begin{array}{l}\text { I imagine that those who are aging are looking back on } \\
\text { life and all the things that they have accomplished. }\end{array}$ \\
\hline Discounts & 2 & $\begin{array}{l}\text { Growing old means that you have access to senior } \\
\text { discounts, senior groups, and affordable housing. }\end{array}$ \\
\hline $\begin{array}{l}\text { Negative } \\
\text { Changes to the } \\
\text { body, weaker, need } \\
\text { care or assistance }\end{array}$ & 14 & $\begin{array}{l}\text { My perceptions of "old" are individuals who are no longer } \\
\text { able to care for themselves. }\end{array}$ \\
\hline
\end{tabular}

Journal of the Scholarship of Teaching and Learning, Vol. 18, No. 2, June 2018.

josotl.indiana.edu 


\begin{tabular}{|c|c|c|}
\hline $\begin{array}{l}\text { Visible signs of } \\
\text { aging }\end{array}$ & 8 & $\begin{array}{l}\text { [This image] depicts an elderly person who is visibly } \\
\text { growing older due to the gray hair on the face and head as } \\
\text { well as having wrinkles on the face...growing old means } \\
\text { that there will be obvious physical changes to one's body } \\
\text { that are obvious to others. }\end{array}$ \\
\hline $\begin{array}{l}\text { Loss of autonomy, } \\
\text { not enough } \\
\text { resources }\end{array}$ & 4 & $\begin{array}{l}\text { [older people] depend on their loves ones, care takers, or } \\
\text { nursing homes to manage their daily living tasks such as } \\
\text { eating, getting dressed, bathing, etc. }\end{array}$ \\
\hline Mental incapacity & 3 & As you age, one begins to forget things. \\
\hline Loneliness & 3 & $\begin{array}{l}\text { I fear...being someone who is possibly lonely, isolated } \\
\text { from family and friends... }\end{array}$ \\
\hline $\begin{array}{l}\text { Scared of getting } \\
\text { old }\end{array}$ & 3 & $\begin{array}{l}\text {...thinking about "old" terrifies me. You never know how } \\
\text { you are going to be when you become } 80 \text { or } 90 \text {. }\end{array}$ \\
\hline Annoying/grumpy & 2 & $\begin{array}{l}\text {...the woman in the picture is old, and has a sort of "don't } \\
\text { bother me" look on her face, which I associate with older } \\
\text { people. }\end{array}$ \\
\hline Death & 2 & $\begin{array}{l}\text { One of my worst fears is...the inevitable process of aging } \\
\text { and dying. }\end{array}$ \\
\hline
\end{tabular}

Only six posts were solely negative. Students who focused on negative aspects of aging primarily mentioned visible signs of aging and physical changes to the body including being weak, vulnerable, or in need of assistance. Some also pointed to mental incapacity, loneliness, and loss of autonomy as hallmark of their perspective on aging. A few even mentioned that the thought of "being old" was "terrifying." This post is representative of that category:

I have always been scared of getting old...it is an unknown future and it scares me. I see what the media shows...mental deterioration, physical deterioration, and a time of helplessness...relying on others, not having enough resources, being unaware, and annoying to others.

Table 2 also provides the negative messages, their frequencies, and short illustrative quotes.

\section{Discussion 2: Processing Images as a Group}

Students' processing of the images was consistent with the content analysis that I conducted on the images and posts for Discussion 1 . The most frequently identified pattern amongst the images that students named was the idea that aging is a journey, a process, or stage of life ( $n=16)$. One student wrote, "Everyone will have the same narrowing path, and everyone's candle will unavoidably burn out." The next most frequent pattern that students identified was physical changes in appearance $(n=13)$. One student wrote, "the pattern I notice most was the elderly depicted in an older and near death way.” Physical decline was mentioned slightly more often $(n=7)$ than wisdom $(n=5)$. The final pattern that students noted was that aging was beautiful or in the eye of the beholder $(n=3)$. Interestingly, three students indicated that most of the images were negative, and another three felt that most of the images were positive; these responses were across the two different slide sets.

Overlapping themes emerged between the recognized patterns found in the images and the cultural representations present in the images, which is to be expected given that the patterns are reflective of social attitudes toward older people. In terms of cultural messages in the images, 
negative stereotypes were the mostly highly identified theme $(n=17)$ and students wrote that the cultural message is "aging is bad," "there is a large concentration on youth and beauty," and "you will need assistance in old age." Another student wrote, "There are certain stereotypes that go along with aging including memory loss, increased grumpiness, financial stability, decrease in sexuality, burdens to society, etc.” Five students felt that the images promoted a cultural message that old age is associated with wisdom and being respected, and another five students felt that the cultural message communicated in the photographs was that "being old does not mean you are going to be alone.”

Lastly, students were almost evenly divided on their reaction to the question: "how does it make you feel to think about being 'old'?” Fourteen students had positive perspectives on the aging process stating messages such as: "my grandma prepared me and I'm not afraid to be old," "I'm going to make the best of it and have fun," and "aging can be beautiful." Twelve students expressed fears about the aging process and growing older. These fears were mostly associated with health, and one student wrote, "I am worried that I will not be able to take care of myself and depend on others.” For another student, she simply stated, "I don't like to think about growing older." For six other students, they expressed a mixture of positive and negative feelings about growing older. This student's post is representative of those feelings,

After reviewing these pictures, I feel that I am both afraid to get older, but also okay with the process. I am not fearful because I am excited to see where life takes me in that time. However, I am scared to think about what I will not complete in my life. Will I look back and have years of regret? Will I be alone or will I lose my independence?

\section{Quantitative Findings}

Given that tests of significance could not be completed, descriptive information on the quantitative measures are provided to provide a snapshot of student attitudes and beliefs. On Survey 1 , the average ageism score for the participants was mostly positive with a mean of 44.18 (range $=30-67$ ). The average ageism score on Survey 2 was slightly lower at 42.67 (range=2772). For both survey responses, none of the students approached the upper ends of the scale indicating that while they may have held some ageist beliefs, on the whole, the students rejected ageist statements. Similarly, students indicated a relatively high average likelihood of working with older people after finishing their degree ( $M=4.48$; range 1-6), and on Survey 2 the average was nearly identical $(M=4.43)$. Finally, students reported on average that their feelings about working with older adults changed somewhat. Specifically, 19 of the 28 students chose either "somewhat" or "a great deal" to describe the extent of their change while nine chose either "not at all” or "very little." The item did not specify if this change was positive or negative; however, evidence from the open-ended questions suggested that if change occurred for a student that it was indeed positive (described below). This item was found only on Survey 2. Table 3 provides further descriptive information on these measures.

Journal of the Scholarship of Teaching and Learning, Vol. 18, No. 2, June 2018.

josotl.indiana.edu 


\section{Table 3. Results of Quantitative Measures}

\begin{tabular}{lrr}
\hline Variable & Survey 1 & \multicolumn{1}{c}{ Survey 2 } \\
\hline Ageism & $44.18(9.15)$ & $42.67(10.80)$ \\
Likelihood of working with OA & $4.48(1.33)$ & $4.43(1.32)$ \\
Very unlikely & $1(3.0 \%)$ & $1(3.6 \%)$ \\
Unlikely & $2(6.1 \%)$ & $1(3.6 \%)$ \\
Somewhat unlikely & $3(9.1 \%)$ & $4(14.3 \%)$ \\
Somewhat likely & $10(30.3 \%)$ & $8(28.6 \%)$ \\
Likely & $8(24.2 \%)$ & $7(25.0 \%)$ \\
Very likely & $9(27.3 \%)$ & $7(25.0 \%)$ \\
Change in feelings about gero & --- & $2.79(1.07)$ \\
work & & $5(17.9 \%)$ \\
Not at all & --- & $4(14.3 \%)$ \\
Very little & --- & $11(39.3 \%)$ \\
Somewhat & --- & $8(28.6 \%)$ \\
$\quad$ Great deal & --- &
\end{tabular}

Open-ended Survey Items

On Survey 2, an item that asked students to discuss "why/why not would they work with older people" revealed two main themes amongst the 23 responses that were in favor of working with older adults. Nine students indicated that "people are people, young or old” even though society diminishes them. One student wrote,

I do believe that older adults are very valuable in society, a lot more valuable than we show them that they are. I think ageism and stereotypes fall heavily on this population. I think a lot of people are less sensitive to it, because we know that they are at the end of their lives. Many of their ailments tend to weigh heavily on those close who take care of them. Which may also breed towards an overall culture of resentment in a very individualistic society.

Seven students noted that they enjoyed working with older adults or were looking forward to working with older people. Five students included both of these two themes in their responses, such as this student,

Working with older adults appeals to me because this is a very underserved population. I have always enjoyed working with older people and feel like I would be a great advocate for the older adult. I also find older adults very interesting and am interested in helping them quality of life in their later years.

The final two students indicated that they did not want to work with older adults because they had chosen another field of practice.

On the item in Survey 2 that asked students to share any other thoughts that they might have on gerontological practice or the course, 15 students responded. Two of these responses were related to how practice with older adults is rewarding, while the other 13 responses were related to the course. Students indicated that it was a "great course," and they "learned a lot." Other students expressed increased comfort in working with older adults, that their opinions about older adults were shaped by the course, and "it opened my eyes to issues that I was not aware of." One student further articulates this change, 
The class was interesting and made me think about topics that are not really touched on, such as sexuality and prison among the elderly. I also became more aware of my own stereotypes of the elderly such as "how cute" they are. Moreover, I am more aware of my interactions among the elderly since this class and have a better understanding of the population.

\section{Discussion}

Results across the different measurement approaches indicated that students experienced a challenge to their thinking about older people, in particular cultural and individual stereotyping. These changes cannot be attributed to the photography activity in-and-of-itself. Rather, the shifts in thinking about gerontological work or about older people in general were likely the result of the combination of learning activities, including readings and lecture. However, the photo activities offered a way to incorporate a visual approach to stimulate critical thinking in an online course, and one that appeals to generational needs. Future research should seek to garner direct feedback on the activity itself. Anecdotally, several students included their thoughts about using images in their posts writing things such as this: "I thoroughly enjoyed looking at all the pictures that everyone felt was their definition of aging or getting older.” A more formal evaluation could elicit specific feedback on how to improve the activities.

The overwhelmingly positive attitudes toward older people amongst this group of students may be attributed to their positive contact with older adults or their previous work experience with older people given that the literature consistently points to these experiential factors as having a profound impact on attitudes toward gerontological practice (Allen \& Johnson, 2008; Chonody \& Wang, 2014; Chonody, Webb, Ranzijin, \& Bryan, 2014; Goncalves, 2009). While this cannot be tested given the small number of participants, students reported spending time with an older person and that the relationship was good. Students also mentioned their previous work experiences (e.g., nursing assistant) in open-ended questions on the survey and related this to their desire to work in this field. Increased service learning and experiential activities with community dwelling older adults, such as intergenerational arts programs, are likely necessary to truly make an impact on students' interest in working with older people (Chonody, 2015; Goncalves, 2009).

In both posts, students identified wisdom, knowledge, good stories, and the chance to learn from older people. The opportunity that gerontological practice offers to learn from older adults' experiences is consistent with past findings that have highlighted this as one of the key benefits of working with older people (Webb, Chonody, Ranzijin, Owen, \& Bryan, 2015). Similarly, the negative aspects of this practice area were realized in the images that students picked for their post; that is, showing older people who are infirm, dependent, sad, or lonely. In other student studies, these types of sentiments have also been found (e.g., Mason \& Sanders, 2004; Webb et al., 2015). These results suggest that the photo activities can draw out the positive and negative sentiments expressed toward older people and practice in this area, which points to its utility in challenging students' thinking about these issues. Future research should seek to test if these methods can challenge ageist biases when the activities are couched in a more general course (e.g., Human Behavior in the Social Environment; Introduction to Psychology/Sociology).

Journal of the Scholarship of Teaching and Learning, Vol. 18, No. 2, June 2018. 


\section{Limitations}

The findings from this study must be considered within the context of its limitations. First, the number of participants in this case study was small and was drawn from one social work program in the Midwest. Results are not generalizable to other social work students; however, the results do point to a promising pedagogical activity that could be readily incorporated into an online course or modified and utilized in a traditional, face-to-face course. Additional research is needed to show its utility in other courses, and to better understand how these photo-activities may address issues of ageism or aging stereotypes.

Second, the inability to compare the quantitative measures from Survey 1 to Survey 2 was a limitation in this study. The development an anonymous survey with a mechanism for linking the surveys would have strengthened the design. However, it should be noted that the measurement approach chosen for this study may not have been sensitive enough to measure change for social work students who may be only experiencing subtle shifts in their perceptions of older people. In other words, items may be too blatant in their ageist sentiments for social work students (especially graduate students) who have received a substantial amount of education on social justice and oppressed populations. Relatedly, given this exposure, the inclusion of a social desirability scale would allow an assessment of student responding.

\section{Conclusion}

In sum, this pedagogical activity sought to couple critical thinking, self-reflection, and discussion to broaden student attitudes toward older adults and gerontological social work practice. Specifically, the aim was to facilitate the deconstruction of aging myths and the false dichotomization of young/old by challenging students' thinking about what it means to be "old" and how they perceive their aging process. This study adds to the burgeoning literature on evidence-based instructional techniques for online courses and the substantive knowledge base regarding attitudinal change amongst college students. Online pedagogy that facilitates critical thinking can be advanced through the development of innovative ways to engage students online by repurposing technology that they are already using.

\section{References}

Allen, L. J., \& Johnson, J. A. (2008). Undergraduate attitudes toward the elderly: The role of knowledge, contact, and aging anxiety. Educational Gerontology, 35(1), 1-14.

Allport, G. W. (1954). The nature of prejudice. New York: Doubleday.

Barrett, A. E., \& Pai, M. (2008). Sketches in cyberspace: Using drawings of elders in an online social gerontology course. Gerontology \& Geriatrics Education, 29, 84-103.

Black, A. (2011). Making meaning with narrative shapes: What arts-based research methods offer educational practitioners and researchers. Studies in Learning, Evaluation, Innovation, and Development, 8(2), 67-82. 
Butler, F. R., \& Baghi, H. (2008). Using the internet to facilitate positive attitudes of college students toward aging and working with older adults. Journal of Intergenerational Relationships, $6,175-189$.

Castillo, J. L. A., Camara, C. P., \& Eguizabal, A. J. (2011). Prejudice reduction in university programs for older adults. Educational Gerontology, 37, 164-190.

Chio, V. C. M., \& Fandt, P. M. (2007). Photovoice in the diversity classroom: Engagement, voice, and the "eye/I" of the camera. Journal of Management Education, 31(4), 484-504.

Chonody, J. M. (2015). Addressing ageism amongst students: A systematic review of the pedagogical intervention literature. Educational Gerontology, 41, 859-887.

Chonody, J. M., \& Amitrani-Welsh, J. (2014). Imaging change: Photography as an instrument of practice. In J. M. Chonody (Ed.), Community art: Creative approaches to practice (pp. 9-25). Champaign, IL: Common Ground.

Chonody, J. M., Ferman, B., Martin, T., \& Amitrani-Welsh, J. (2013). Violence through the eyes of youth: A photovoice exploration. Journal of Community Psychology, 41, 84-101.

Chonody, J. M., \& Wang, D. (2014). Student interest in aging: Predictors from an international perspective. Journal of Gerontological Social Work, 57, 773-789.

Chonody, J. M., Webb, S., Ranzijn, R., \& Bryan, J. (2014). Working with older adults: Predictors of attitudes to aging in social work and psychology students, faculty, and practitioners. Australian Psychologist, 49, 374-383.

Collier, J. (1957). Photography in anthropology: A report on two experiments. American Anthropologist, 59(5), 843-859.

Federal Interagency Forum on Aging-Related Statistics. (2010). Older Americans 2010: Key indicators of well-being. Washington, DC: U.S. Government Printing Office.

Fraboni, M., Saltstone, R., \& Hughes, S. (1990). The Fraboni Scale of Ageism (FSA): An attempt at a more precise measure of ageism. Canadian Journal on Aging, 9, 59-66.

Funderburk, B., Damron-Rodriguez, J., Storms, L. L., \& Solomon, D. H. (2006). Endurance of undergraduate attitudes toward older adults. Educational Gerontology, 32, 447-462.

Gonçlaves, D. C. (2009). From loving grandma to working with older adults: Promoting positive attitudes towards aging. Educational Gerontology, 35(3), $202[\mathrm{Z} 25$.

Goncalves, D. C., Guedes, J., Fonseca, A. M., Pinto, F. C., Martin, I., Byrne, G. J., \& Pachana, N. A. (2011). Attitudes, knowledge, and interest: Preparing university students to work in an aging world. International Psychogeriatrics, 23, 315-321. 
Gutheil, I. A., Chernesky, R. H., \& Sherratt, M. L. (2006). Influencing student attitudes toward older adults: Results of a service-learning collaboration. Educational Gerontology, 32, 771-784.

Hagedorn, M. I. E. (1996). Photography an aesthetic technique for nursing inquiry. Issues in Mental Health Nursing, 17, 517-527.

Harper, D. (2002). Talking about pictures: A case for photo elicitation. Visual Studies, 17(1), 13-26.

Harrison, B. (2002). Photographic visions and narrative inquiry. Narrative Inquiry, 12(1), 87111.

Hwang, H.-L., Wang, H.-H., \& Lin, H.-S. (2013). Effectiveness of supervised intergenerational service learning in long-term care facilities on the attitudes, self-transcendence, and caring behaviors among nursing students: A quasiexperimental study. Educational Gerontology, 39, 655-668.

Kane, M. N. (2007). Social work and criminal justice students’ perceptions of elders. Journal of Social Service Research, 34, 13-26.

King, B. J., Roberts, T. J., \& Bowers, B. J. (2013). Nursing student attitudes toward and preferences for working with older adults. Gerontology \& geriatrics education, 34(3), 272-291.

Leavy, P. (2009). Method meets art: Arts-based research practice. New York: Guilford Press. Mason, S., \& Sanders, G. (2004). Social work students' attitudes on working with older clients. Journal of Gerontological Social Work, 42(3/4), 61-75.

O’Hanlon, A. M., \& Brookover, B. C. (2002). Assessing changes in attitudes about aging: Personal reflections and a standardized measure. Educational Gerontology, 28, 711-725. Ott Walter, K., Baller, S. L., \& Kuntz, A. M. (2012). Two approaches for using web sharing and photography assignments to increase critical thinking in the health sciences. International Journal of Teaching and Learning in Higher Education, 24(3), 383-394.

Robinson-Kellig, R. A., Hamill, C., Gwin-Vinsant, A., \& Dashner, M. (2014). Feminist pedagogy in action: Photovoice as an experiential class project. Psychology of Women Quarterly, 38, 292-297.

Snyder, J. R. (2006). The influence of instruction on college students' attitudes toward older adults. Gerontology \& Geriatrics Education, 26, 69-79.

Tornabene, L., Versnik Nowak, A., \& Vogelsang, L. (2012). Using the fotofeedback method to increase reflective learning in the millennial generation. The Journal of Effective Teaching, 12(2), 80-90. 
Van Dijck, J. (2008). Digital photography: Communication, identity, memory. Visual communication, 7(1), 57-76.

Wang, C. C., \& Burris, M. A. (1997). Photovoice: Concept, methodology, and use for participatory needs assessment. Health Education \& Behavior, 24, 369-387.

Wang, D., \& Chonody, J. M. (2013). Social workers' attitudes toward older adults: A review of the literature. Journal of Social Work Education, 49, 150-172.

Webb, S., Chonody, J. M., Ranzijn, R., Owen, M., \& Bryan, J. (2015). A qualitative investigation of gerontological practice: The views of social work and psychology students, faculty, and practitioners. Gerontology \& Geriatrics Education, 37, 402-422.

Weiss, I. (2005). Innovations in gerontological social work education interest in working with the elderly: A cross-national study of graduating social work students. Journal of Social Work Education, 41, 379-391.

Weiser, J. (2013). Phototherapy techniques in counseling and therapy. Retrieved from http://www.phototherapy-centre.com/home.htm. 